\title{
State of mechanical condition applied to industrial machines based on SVD method
}

\author{
Estado de la condición mecánica aplicado a \\ máquinas industriales basado en el método SVD \\ Tomasz Kałaczyński $^{1} \quad$ Ronald M. Martinod ${ }^{2 *}$ \\ Recibido 5 de mayo de 2016, aceptado 22 de abril de 2017 \\ Received: May 5, 2016. Accepted: April 22, 2017
}

\begin{abstract}
A problem related to the operation of industrial machines has been the identification of the mechanical condition in exploitation, via dynamic performance variables which affect the nominal behavior of machine tasks. This paper proposes a set of algorithms focused on identifying of the mechanical condition industrial machines. Therefore, a tool to the maintenance based on the condition is developed; the methodology proposed is focused on the identification of the mechanical condition through recording dynamic variables by applying vibro-estimators techniques via Single Value Decomposition (SVD) method, and development of experimental tests on industrial machines. The work has been conducted on two sets of measurements from a real case study on two identical machines, one machine having nominal operation behavior, and the other machine having a dynamic problem.
\end{abstract}

Keywords: Industrial machine, mechanical condition, failure identification, singular value decomposition, vibration analysis.

\section{RESUMEN}

Un problema relacionado con la operación de máquinas industriales ha sido la identificación de la condición mecánica en operación, utilizando variables de rendimiento dinámico que afectan el proceso nominal de las tareas de la máquina. Este trabajo propone un conjunto de algoritmos centrados en la identificación de la condición mecánica aplicado a máquinas industriales, por tanto, se desarrolla una herramienta para el mantenimiento basado en la condición; la metodología propuesta se centra en la identificación de la condición de máquinas por medio del registro de variables dinámicas en condiciones de funcionamiento, mediante la aplicación de técnicas con vibroestimadores con el método de descomposición de valor singular (SVD) y desarrollo de pruebas experimentales en máquinas industriales. El trabajo se aplica a un caso real llevado a cabo en dos conjuntos de mediciones sobre dos máquinas idénticas, una máquina con el comportamiento de funcionamiento nominal y la otra máquina con un problema dinámico.

Palabras clave: Análisis de vibración, condición mecánica, descomposición de valor singular, identificación de fallo, máquina industrial.

\footnotetext{
1 Wydział Inżynierii Mechanicznej. Uniwersytet Technologiczno-Przyrodniczy. Ul. S. Kaliskiego 7, 85-796. Bydgoszcz, Poland. E-mail: kalaczynskit@mail.utp.edu.pl

2 Departamento de Ingeniería Mecánica. Universidad EAFIT. Cra. 49 № 7 Sur 50. Medellín, Colombia.

E-mail: rmartino@eafit.edu.co

* Corresponding author.
} 


\section{INTRODUCTION}

Vibrations are an intrinsic effect in engineering systems (civil structures, mechanical systems such as airplanes, vehicles, boats, mobile machinery and others); especially in machines, which work in a changing environment or under dynamic load. The vibrations can be: (i) harmful, (ii) useful, or (iii) a source of information [1]. The classical analysis of vibrations focuses on the mechanical behavior after overcoming a level of the threshold by the amplitude or frequency domain, which for different types of machines has been defined by national standards (e.g. Polish Standard-PN-) or international standards (e.g. ISO) [2]. But, to determine the mechanical condition of a machine, the natural vibration process during the lifetime can be used as source of information [3].

The state of mechanical condition applied to engineering systems can be described through a set of parameter values in a given moment of a dynamic time, $t[4,5]$. The time series of the condition mechanical state could be considered as the time of machine operating time, $\Theta$. Using mathematical methods of assessment (forecastting, correlation functions, etc.) allows the qualification of the state of mechanical condition of machines in a particular period of time [6, 7].

The state of art includes studies $[8,9]$ that have been focused on the mechanical modelling of the dynamic variation, considering the change of the loads to assess the mechanical condition. The dynamic assessment of the mechanical condition requires the association of their functional parameters (state features) through measurement dataset $Y(t, \Theta)=\left\{y_{1}\right.$, $\left.y_{2}, \ldots y_{\mathrm{n}}\right\}$, and an analysis of the associated physical processes $\Gamma(X, S)$, to get the symptom dataset $S(T, \Theta)=\left\{s_{1}, s_{2}, \ldots s_{\mathrm{n}}\right\}$ (see Figure 1).

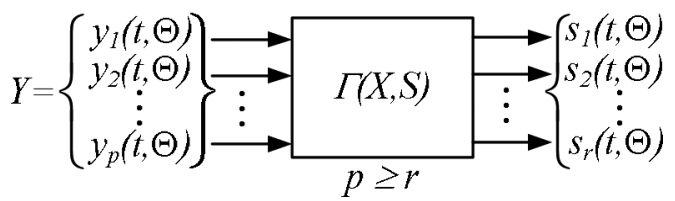

Figure 1. Relationship between measurement and symptom dataset [9].

Previous studies [9, 10] has been exposed methodologies of technical assessment in order to get a mechanical condition assessment through theoretical or analytical models, without a implementation of an applied case.

Other studies [11-13] have used the Singular Value Decomposition (SVD) method in order to obtain different modes of failure. In the other hand, researchers [14-16] have demonstrated that the SVD method is an appropriate tool for analyzing a mapping from one space vector into another, possibly with a different dimensional vectoring. Others studies $[12,17]$ applied SVD to get an appropriate set of symptoms in the observation matrix, $S(t, \Theta)$.

A set of researchers $[15,17,18]$ presented a validation of mechanical condition assessment from the SVD method, the researches obtained signals, which was generated by vibration of a vehicle engine, and the influence of the engine in the variation of the vibro-acoustic data was analyzed, and the influence of the engine in the variation of the vibro-acoustic data was analyzed; then, using the SVD method was possible to identify which symptoms in the observation matrix has better information to assess the state of mechanical condition of combustion engines; nevertheless, the tests were developed on laboratory conditions (using a bed test), then, an analysis in operation real condition not was feasible.

The reviewed literature has a limited scope, due to the theoretical SVD workframe has been applied to engineering systems with controlled conditions. This paper proposes an implementation of the SVD method via recording of dynamic variables, using vibro-estimators technique; then, the study aims to develop an experimental test on industrial machines in a manufacturing process to assess the its state of mechanical condition.

Below, the abbreviations, acronyms, coefficients and constants are presented which will be used throughout the paper:

FFT Fast Fourier Transform.

PDF Probability Density Function.

MD Multivariable Diagnostic.

SIBI Computer System of Identification Investigations.

SVD Singular Value Decomposition.

A Probability of unnecessary reparations.

$G \quad$ Reliability of the system on service. 
$F_{i} \quad i^{\text {th }}$ function of failure progress.

$P_{i} \quad$ Measurement points

$S \quad$ Symptom matrix observation.

$S D_{i} \quad i^{t h}$ discriminant of failure.

$t \quad$ Dynamic time domain.

$U_{p p}, V_{r r}$ Left and right orthogonal singular matrix, respectively.

$v_{i}, u_{i} \quad i^{\text {th }}$ eigenvector components.

$w_{F} \quad$ Failure condition hypothesis.

$w_{G} \quad$ Good condition hypothesis.

$w_{u} \quad$ Bayes decision rule from hypothesis.

$\sigma_{i} \quad i^{\text {th }}$ eigenvalue.

$\phi_{p r} \quad$ System variation.

$\Sigma_{p r} \quad$ Diagonal matrix of the singular values.

$\Theta \quad$ Machine operation time, lifetime.

\section{THEORETICAL ANALYSIS}

Given a set of symptoms $S \in \mathbb{R}^{p \times r}$ from vibroacoustic signals which describe the mechanical condition, i.e. it contains relevant information about the state of the technical behavior [15]. The general procedure is shown in Figure 2.

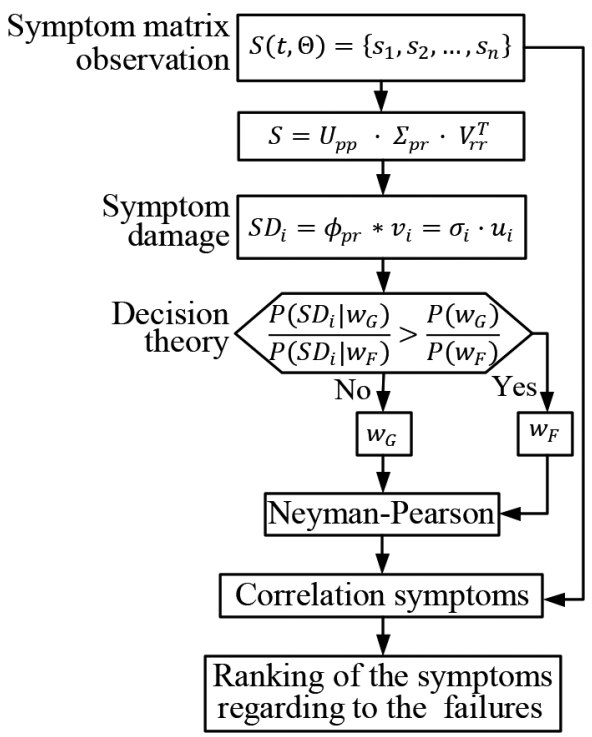

Figure 2. General diagram flow of the procedure.

The SVD method to dimension the symptoms observation matrix, is expressed as follows $[13,15]$

$$
S=U_{P P} \cdot \sum_{p p} \cdot V_{r r}^{T},
$$

where $\Sigma_{p r}$ is the main diagonal matrix of the singular values, then $\Sigma_{p r}=\operatorname{diag}\left(\left\{\sigma_{1}, \ldots, \sigma_{i}\right\}\right)$ becomes the eigenvalues with a physical interpretation, $\sigma_{i}$ represents the fraction of damage (fault contribution) in the engineering systems. The SVD has the following mathematical property

$$
S D_{i}=\phi_{p r} \cdot v_{i}=\sigma_{i} \cdot u_{i}
$$

where $v_{i}$, and $u_{i}$ are the singular vectors, and $\phi_{p r}$ describes the behavior variation of the system due operational condition, i.e. its wear or its failure modes.

The function of failure progress $F_{i}\left(\Theta_{k}\right)$ in the machine lifetime $\Theta_{k}$ can be described through a discriminant, $S D_{i}\left(\Theta_{k}\right)$. It is therefore possible to affirm that $S D_{i}\left(\Theta_{k}\right) \sim F_{i}\left(\Theta_{k}\right)$ [11].

$S D_{i}$ is a sensible symptom of a specific failure and therefore, each $S D_{i}$ is used to identify a failure between different symptoms that evolve in the system. $S D_{i}$ contains independent information about the failure mode and also on the intensity of this failure $[2,12]$.

The SVD result is analyzed by a joint of $S D_{i}$ and the decision theory concept. Then, two hypotheses in which the symptom will be classified are considered $[11,19]$ : good condition, $w_{G}$; and failure condition, $w_{F}$. The posteriori probability of each condition is $P\left(w_{u} \mid \mathrm{S}\right)$ with $w_{u}=\left\{w_{G}, w_{F}\right\}$, the decision rule using Bayes theory is defined as $w_{G}$ if and only if

$$
\frac{P\left(S \mid w_{G}\right)}{P(S)}>\frac{P\left(S \mid w_{F}\right)}{P(S)},
$$

otherwise is $w_{F}$, where: $P\left(S \mid w_{G}\right)$ is the Probability Density Function (PDF) according to a good symptom condition $S$; and $P\left(S \mid w_{F}\right)$ is the PDF of the failure state of $S$.

The posteriori conditional PDF is got with the a-priori probability $P\left(w_{u}\right)$. Then, the decision rule can be formulated as the probability ratio $w_{G}$ in the case that

$$
\frac{P\left(S \mid w_{G}\right)}{P\left(S \mid w_{F}\right)}>\frac{P\left(w_{G}\right)}{P\left(w_{F}\right)},
$$


And $w_{F}$ in the contrary case. Generally, the bounder of the decision is defined through the equality of the pondered conditional PDFs $P\left(S \mid w_{G}\right) \cdot P\left(w_{G}\right)=P\left(S \mid w_{F}\right)$ $\cdot P\left(w_{F}\right)[11]$.

Neyman-Pearson lemma may be used to get particular test-statistics. Neyman-Pearson allows identifying the error of wrongly classifying a good condition as the beginning of a failure over a probability level of $A$ [21].

$$
A=G \int_{S} P\left(S \mid w_{G}\right) d S=G R(S),
$$

Where $A$ is the probability of unnecessary reparations, and $G$ is the reliability of the system under service. It must be recalled that the preceding integral is nothing else but the reliability of the previously defined symptom $R(S)=\int_{S} P\left(S \mid w_{G}\right) d S$ [22]. The diagnostic of the probability of a wrong classification for a good condition is usually fixed to a low level (e.g. $A=0.05$ ).

The final stage of the analysis is the correlation symptoms procedure with the identified failure, which allows ranking the symptoms due to the correlation coefficient value.

\section{CASE OF STUDY}

This study is applied to industrial machines for lighting elements manufacturing in series (see Figure 3 ). The machines were made by the Philips Co. in the Netherlands, into a production line model HOOR-6002 and the year of production was 1980. The maximum output capacity of the line is 6900 lighting elements per hour (tube lights). The machines are subject to preventive maintenance once a week, and also it is carried out a detailed inspection quarterly basis to review all systems.

The research has been conducted on two identical machines. One machine is having a change in the dynamic state that generates an increased amount of damaged production elements (lighting elements), which will be called fault machine, $M_{F}$. The second machine does not have production errors, representing the nominal behavior of the machine dynamic state, i.e. the second machine shows the reference values, $M_{R}[20]$.

The physical vibration performance has been recorded in a DAQ system by means of a set of single-axial piezoelectric accelerometers, PCB-352C68-ICP model. The signals in time domain recorded from DAQ system were processed to a real-time hardware package; it has been setted as following:

(i) a four-channel module VIBdaq (24 VDC; 2,4 $\mathrm{mA})+$ Anti-aliasing filtering data individually adjusted (gain error $<0.5 \%$ ), and a sampling frequency of 100 kilo-sampling per second with 16 bit resolution; and

(ii) a digital processing signal software called SIGVIEW, which has an optimized FFT algorithm with windowing and zero-padding.

The field test procedure requires a selection of a measurement points set. The criteria to select the measurement points are: (i) structural design of the machine, and (ii) physical access to the particular point in the machine, as well as an appropriate surface to attach the transducer, see Appendix A. The measures are focused on the main bearings due to the characteristic of the type industrial machine

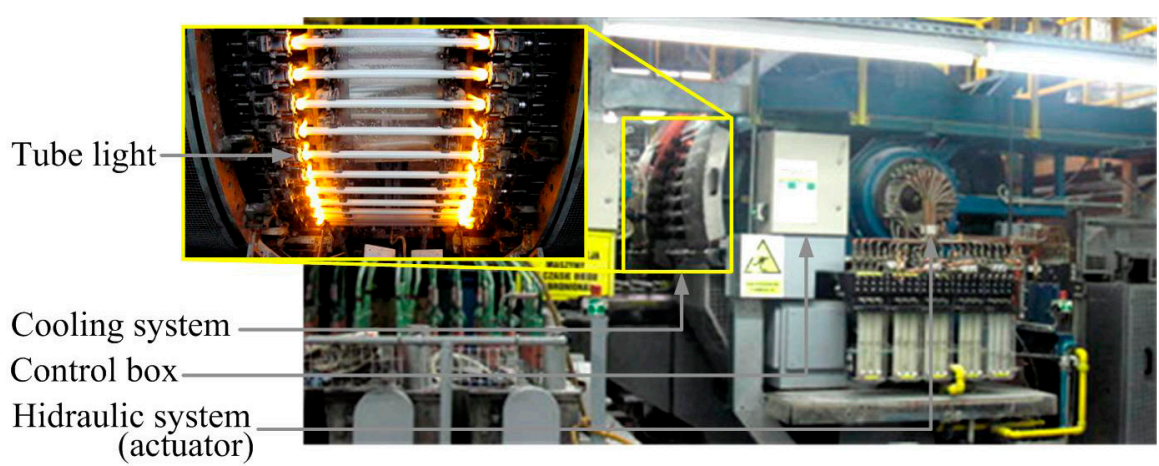

Figure 3. Overview of the engineering system. 
applied as case of study (rotating machine). A total of nine (9) measurement points $P t=\left\{p_{1}, \ldots, p_{9}\right\}$ have been identified on each machine, $M_{F}$ and $M_{R}$. The set of points $\left\{p_{1}, p_{2}, p_{3}, p_{9}\right\}$ has been located on the side of the machine actuator, see Figure 7, and the set of points $\left\{p_{4}, p_{5}, p_{4}, p_{7}, p_{8}\right\}$ on the side of the feed tape, see Figure 8 . The set of points $\left\{p_{1}, p_{2}, p_{3}\right.$, $\left.p_{4}, p_{4}, p_{5}, p_{9}\right\}$ has axial direction related to the main bearings, and the set of points $\left\{p_{7}, p_{8}\right\}$ has radial direction. All datasets recorded are available from the authors of this paper, as an example, the data recorded from $M_{F}$ and $M_{R}$ are shown in Appendix $\mathrm{B}$; a minimum $50 \mathrm{kHz}$ sample frequency has been established, including an anti-aliasing filter setting at a twice sampling frequency. The signals recorded as dataset were transformed to the frequency domain by Fast Fourier Transform (FFT) algorithm. FFT was used to ensure proper excitation in frequency range of interest which from 0 to $8 \mathrm{kHz}$.

\section{ANALYSIS OF RESULTS}

The dataset have been analyzed with an algorithm called Computer System of Identification Investigations (SIBI). SIBI algorithm was used to validate the research results $[2,16]$ and allowed generating a set of symptoms, $S=\left\{x_{\text {ave }}, A_{R M S}, \sigma_{j}, K\right.$, $C, I\}$, which represent: (i) $x_{\text {ave }}$-Average; (ii) $A_{R M S}$ - Root Mean Square amplitude; (iii) $\sigma_{j}-$ Standard deviation; (iv) $I$-Shape factor; (v) $C$-Crest factor; and (vi) $I-$ Impulse factor. The selected symptoms $S_{j}$ are the most common measures used in analyzing the experimental test results for this type of machines; also, these measures have a high sensitivity to the mechanical variation, which allows the identification of the mechanical condition.

$S$ is analyzed by using SVD for the quantitative identification of symptoms related to an individual damage participation $S D_{i}$ [16]. The results of the failures contribution percentage $S D_{i}$ (see Figure 4) show that $M_{R}$ has one representative fault indicator $\left(S D_{1}\right)$, while $M_{F}$ presents an increase in the quantity of fault items $\left(S D_{1}, S D_{2}\right) . S D_{1}$ values indicate a low dynamical level in the machine (verified posteriori), and larger $S D_{2}$ values mean a damage development. Figure 4 shows $S D_{1}$ values decrease from $M_{R}$ to $M_{F}$ (10\% aprox.), and $S D_{2}$ values increase from $M_{R}$ to $M_{F}(10 \%$ aprox.); then, the development of damage is observed which causes the machine faulty behavior.

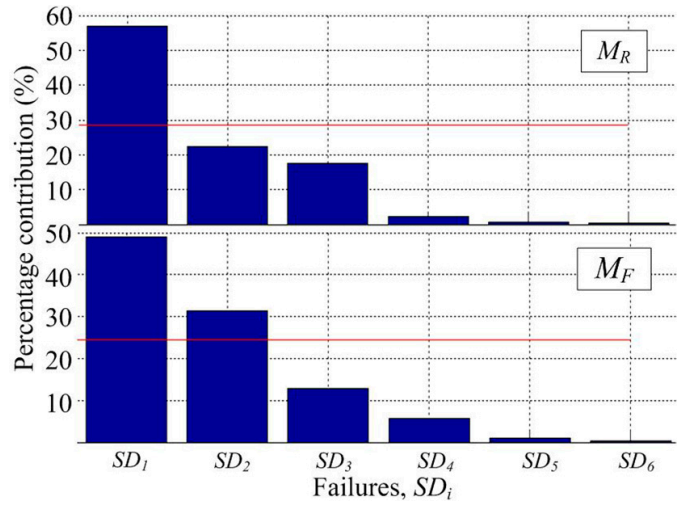

Figure 4. Graphical interpretation of machine failures.

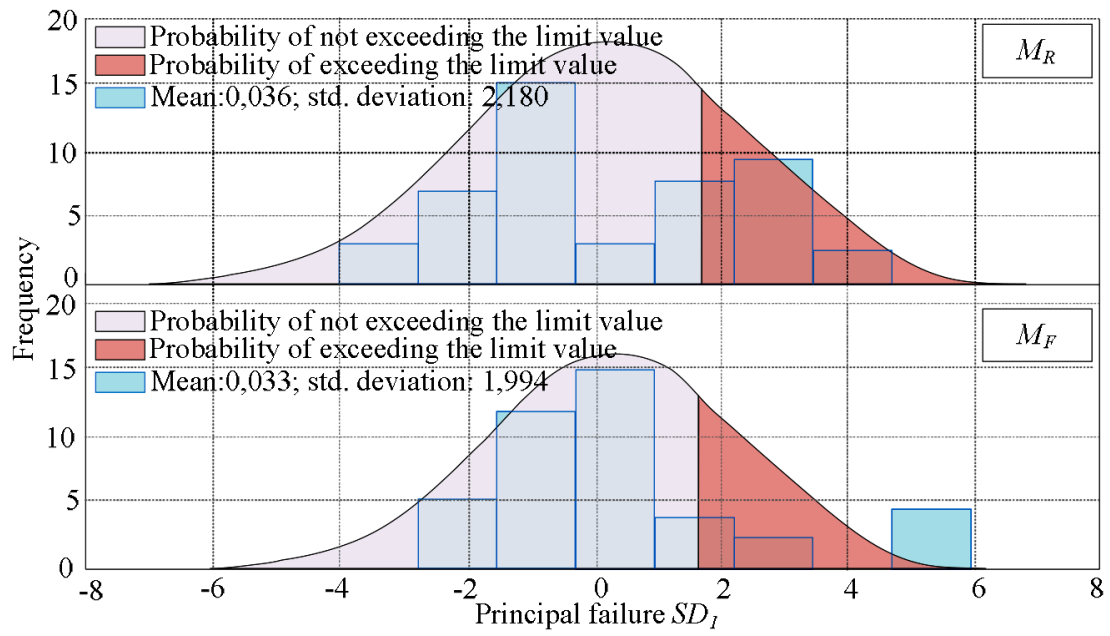

Figure 5. Histogram of the principal fault, $S D_{1}$. 
The histogram of $S D_{1}$ (see Figure 5) allows the failure assessment of the machine. The standard deviation of $S D_{1}$ decreases from $M_{R}$ to $M_{F}(8,5 \%$ aprox.), then, the principal fault converges to a central value, the SVD method allows identify a set of suitable symptoms.

Analysing in detail the principal fault (see Figure 6), it is possible to break down $S D_{1}$ into the eigenvector components to identify the symptoms $S_{j}$, which have the highest level of influence, i.e. the most sensible symptoms regarding the fault.

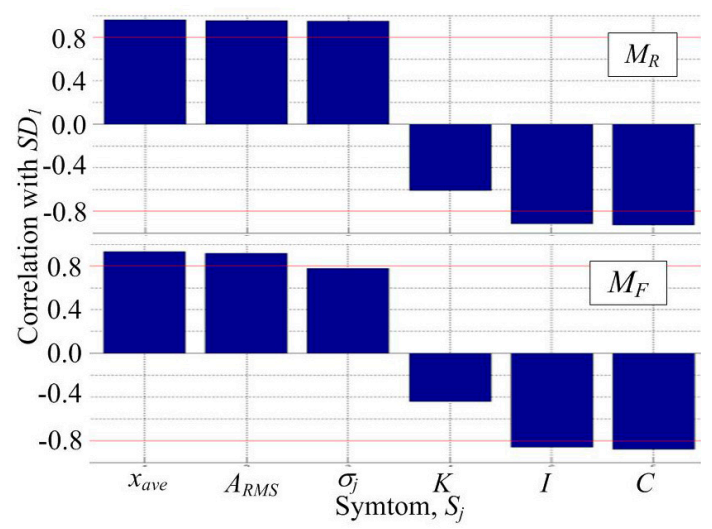

Figure 6. Correlation between symptoms and the principal fault $S D_{1}$.

The values of the symptoms correlation, independent to the dynamic state, show an equal ranking of their participation in quantitative and qualitative assessment of the dynamic state of the machine, it means the results are consistent and they provide a stable index.

The results show the development of damage causes the machine works on fault condition. According to the results from the object to study (rotating machine), the principal fault has been produced in the the main bearing on the side of the equipment. The results also show the influence of an electric motor bearing used to drive the machine.

\section{CONCLUSIONS AND FUTURE WORK}

The vibrations signals allow describing the dynamic condition of machines by a set of indexes (eigenvector components of $S D_{1}$ ) from different symptoms $S=\left\{S_{1}\right.$, $\left.s_{2}, s_{r}\right\}$, which they are related to the fault.
The assessment of mechanical condition based on a multidimensional analysis (vibroacoustics signal) gives the opportunity to identify the relationship between symptoms $S$, whose values have changed as a result of damage.

The proposed method allows ranking the symptoms to describe the machine technical condition and, to identify the damage causes. Besides, this method allows generating a new set of independent symptoms that may be useful for assessment of the mechanical condition; and the method can be used to reject symptoms that do not provide important information about the mechanical condition.

The Neyman-Pearson analysis applied to the main fault, $S D_{1}$, give the probability of not exceeding a limit value, which allows the assessment of importance of damage.

To generate a dynamic map of the mechanical condition, it is necessary to make a series of tests approaching the lifetime of the machine, $\Theta$. This approach will enable monitoring the system to get the mechanical behavior of the machine, thereby increasing its reliability in terms of its implementation in production processes.

The next step of the quantitative and qualitative analysis description of participation symptoms in the assessment of mechanical condition is modelling the cause-effect relationships using multiple regressions analysis.

\section{ACKNOWLEDGEMENT}

This paper is a part of investigative project WND-POIG.01.03.01-00-212/09 (Poland) and COLCIENCIAS (Colombia).

\section{REFERENCES}

[1] C. Zhi-Qiang, M. Yi-Zhong, B. Jing and S. Hua-Ming. "Mean shifts diagnosis and identification in bivariate process using LS-SVM based pattern recognition mode". Int. J. of Industrial Eng.: Theory Applications and Practice. Vol. $20 \mathrm{~N}^{\circ}$ 7, pp. 453-467. 2013.

[2] C. Cempel, M. Tabaszewski, and M. Krakowiak. "Extraction nethods of multifault information in machine condition 
monitoring". Key Engineering Materials. Vols. 245-246, pp. 215-222. 2003.

[3] B. Żółtowski, H. Tylicki, T. Kałaczyński, and L.F. Castañeda. "identification in vibration diagnostics of critical machines", in B. Zółtowski (Ed.): Knowledge Acquisition for Hybrid Systems of Risk Assessment and Critical Machinery Diagnosis. Politechnika Śląska pp. 401-493. 2008.

[4] L.F. Castañeda, R.M. Martinod and G.R. Betancur. "Determination of the technical state of suspension elements based on the OMA-LSCE method". Ingegneria Ferroviaria. Vol. $32 \mathrm{~N}^{\circ}$ 1, pp. 41-54. 2012.

[5] R.M. Martinod, G.R. Betancur and L.F. Castañeda. "Identification of the technical state of suspension elements in railway systems". Int. J. Vehicle System Dynamics, Vol. $50 \mathrm{~N}^{\circ}$ 7, pp. 1121-1135. 2012.

[6] B. Żółtowski and C. Cempel. "Inżynieria diagnostyki maszyn”. Polskie Towarzystwo Diagnostyki Technicznej. Warszawa, Poland. 2004.

[7] B. Żóttowski. "Diagnostic system maintenance the ability of machines" (in Polish). Maintenance and Reliability. Vol. 36, No 4 , pp. 72-77. 2007.

[8] J.I Park and S.J. Bae. "Weighted rank regression with dummy variables for analyzing accelerated life testing data". Int. J. of Industrial Engineering: Theory Applications and Practice. Vol. $17 \mathrm{~N}^{\circ} 3$, pp. 236-245. 2010.

[9] C. Cempel. "Evolutionary symptom models in machine diagnostics" (in Polish). Int. Congr. Tech. Diagnostics. Gdańsk, Poland, October. 1996.

[10] H.J. Smadi and A.K. Kamrani. "Product quality-based methodology for machine failure analysis and prediction". Int. J. of Industrial Eng.: Theory Applications and Practice. Vol. $18 \mathrm{~N}^{\circ}$ 11, pp. 568-581. 2011.

[11] H. Natke and C. Cempel. "Model-aided diagnosis of mechanical systems-fundamentals, detection, localization and assessment". Springer. Berlin. 1997.

[12] H. Natke and C. Cempel. "The symptom observation matrix for monitoring and diagnosis". J. of Sound and Vibration. Vol. 248, pp. 597-620. 2001.
[13] B. Żółtowski. "The investigation of the technical condition of railway systems". J. of KONES Powertrain and Transport, Vol. 19 $\mathrm{N}^{\circ}$ 2, pp. 591-600. 2012.

[14] C. Cempel. "Multidimensional condition monitoring of machines in nonstationary operation". ICSV12 Proceedings of Int. Congr. Sound and Vibration. Vol. 496. Lisbon, Spain. 2005.

[15] T. Kałaczyński and M. Łukasiewicz. "Multidimensional analysis and assessment of combustion engine technical state basis on SVD method with modern engineers software application". J. of Polish CIMAC. Vol. 7 No 2, pp. 65-78. 2012.

[16] M.R. Piña-Monarrez. "A new theory in multiple linear regression". Int. J. of Industrial Eng.: Theory Applications and Practice. Vol. $18 \mathrm{~N}^{\circ} 6$, pp. 310-316. 2011.

[17] C. Cempel. "SVD Decomposition of symptom observation matrix as the help in a quality assessment of a group of applications". Diagnostyka. Vol. 35, pp. 7-12. 2005.

[18] R.M. Martinod, G.R. Betancur, L.F. Castañeda, T. Kałaczyński and M. Zółtowski. "Estimation of combustion engine technical state by multidimensional analysis using SVD method". Int. J. of Vehicle Systems Modelling and Testing. Vol. $8 \mathrm{~N}^{\circ} 2$, pp. 105118. 2013.

[19] M. Żółtowski and R.M. Martinod. "Technical condition assessment of masonry structural components using Frequency Response Function (FRF)". Masonry International. Vol. $29 \mathrm{~N}^{\circ}$ 1. 2016.

[20] R.M. Martinod and M. Zółtowski. "Quality identification methodology applied to wall-elements based on modal analysis". Multidiscipline Modeling in Materials and Structures. Vol. $11 \mathrm{~N}^{\circ}$ 4, pp. 507-516. 2015.

[21] V. Bayer and C. Bucher. "Importance Sampling for First Passage Problems of Nonlinear Structures". J. Probabilistic Engineering Mechanics. Vol. 14, pp. 27-32. 1999.

[22] C. Papadimitriou, H.F. Lam and L.S. Katafygiotis. "A Probabilistic Approach to Structural Model Updating". J. Soil Dynamics and Earthquake Engineering. Vol. 17, pp 495-507. 1998. 


\section{APPENDIX A}

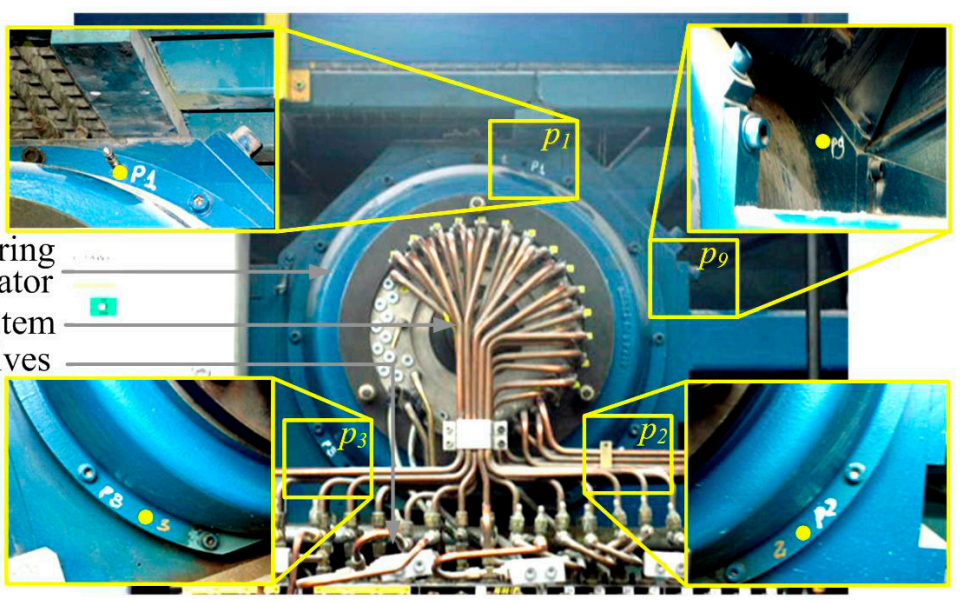

Figure 7. Measurement points on the side of the machine actuator.

Main bearing support of actuato

Hidraulic system

Hidraulic valves

Main bearing support of feed tape

Electric box

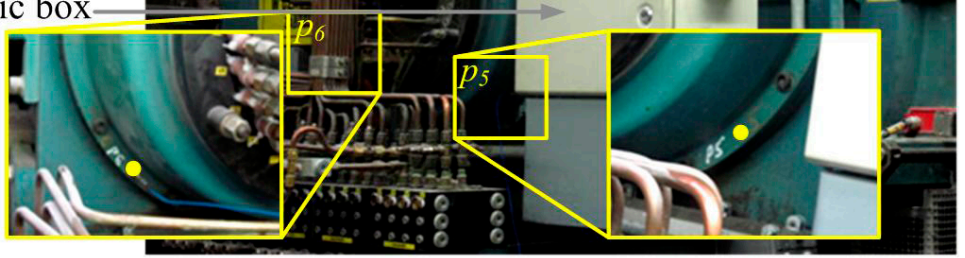

Figure 8. Measurement points on the side of the feed tape. 


\section{APPENDIX B}

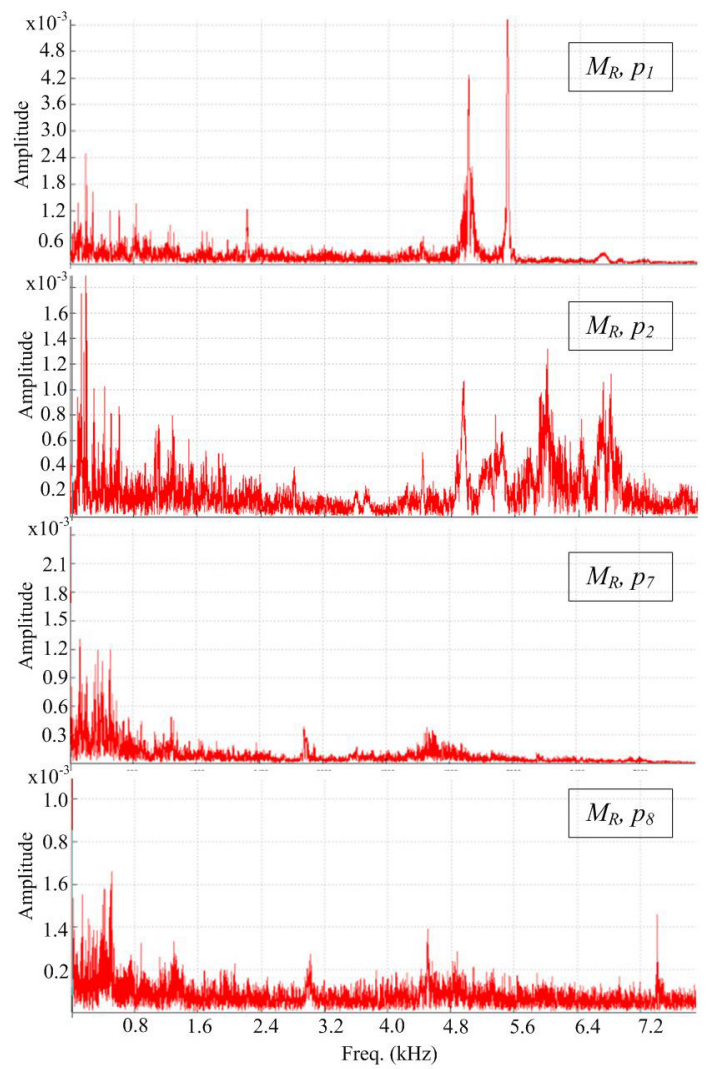

Figure 9. Frequency domain response of recorded signals from reference machine, $M_{R}$.

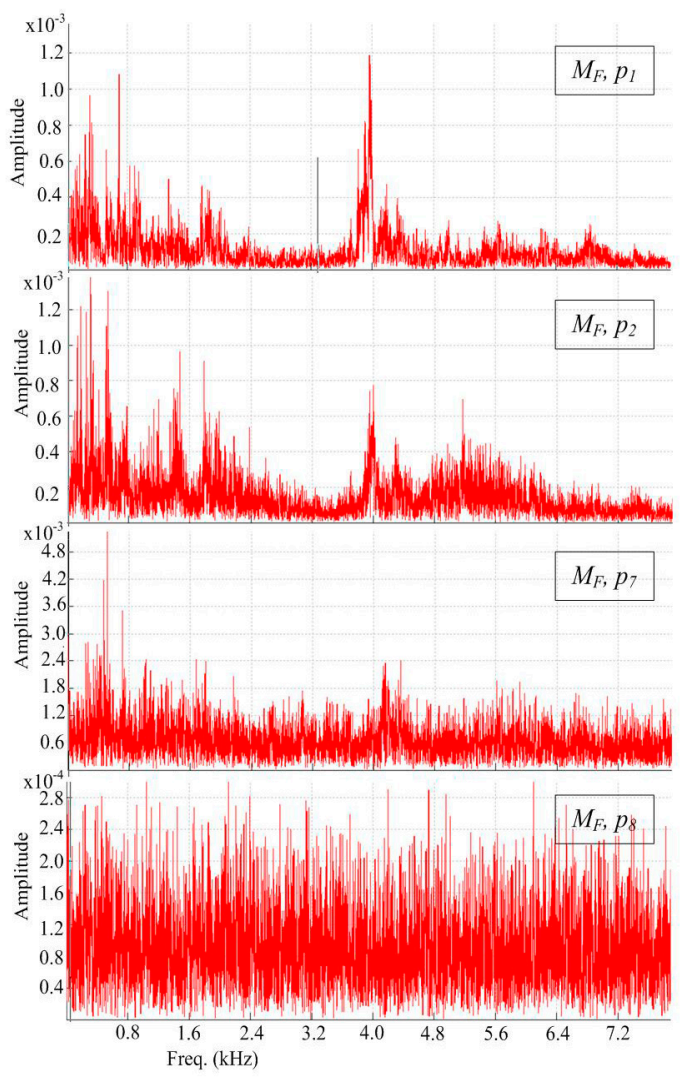

Figure 10. Frequency domain response of recorded signals from fault machine, $M_{F}$. 